Tropical Journal of Pharmaceutical Research January 2021; 20 (1): 95-103

ISSN: $1596-5996$ (print); 1596-9827 (electronic)

(C) Pharmacotherapy Group, Faculty of Pharmacy, University of Benin, Benin City, 300001 Nigeria.

\title{
Antidiabetic potential of Moringa oleifera Lam. leaf extract in type 2 diabetic rats, and its mechanism of action
}

\author{
Tarique Anwer ${ }^{1 *}$, Mohammed M Safhi ${ }^{1}$, Hafiz A Makeen ${ }^{2}$, Saeed Alshahrani ${ }^{1}$, \\ Rahimullah Siddiqui ${ }^{1}$, SM Sivakumar ${ }^{3}$, Emad S Shaheen ${ }^{4}$, Mohammad Firoz \\ Alam ${ }^{1}$ \\ ${ }^{1}$ Department of Pharmacology \& Toxicology, ${ }^{2}$ Department of Clinical Pharmacy, ${ }^{3}$ Department of Pharmaceutics, College of \\ Pharmacy, ${ }^{4}$ Medical Research Center, Jazan University, Gizan, Saudi Arabia
}

*For correspondence: Email: anwer.tariq@gmail.com, tanwer@jazanu.edu.sa; Tel: 00966-565772249

\begin{abstract}
Purpose: To explore the antidiabetic potential of Moringa oleifera leaf extract in type 2 diabetic rats, and the underlying mechanisms.

Methods: Streptozotocin (STZ) at a dose of $40 \mathrm{mg} / \mathrm{kg}$ was given to high fat diet (HFD)- fed rats to induce type 2 diabetes. M. oleifera leaf extract at doses 100, 200 and $400 \mathrm{mg} / \mathrm{kg}$ were given to 3 groups of type 2 diabetic rats. The area under curve (AUC) of glucose and homeostasis model assessment of insulin resistance (HOMA-R) were calculated using appropriate formulas, whereas levels of glucose, insulin, peroxisome proliferator activated receptor-y (PPARY, dipeptidyl peptidase-IV (DPP-IV) and inflammatory cytokines (IL-6, IL-1 $\beta$ and TNF $\alpha$ ) were assayed using ELISA kits.

Results: The leaf extract of $M$. oleifera significantly reduced the levels of glucose, insulin and cytokines in treated type 2 diabetic groups $(p<0.05)$. DC group had significantly increased AUC for glucose, whereas the extract-treated groups showed significant decrease in glucose AUC. There was significant decrease in insulin sensitivity parameters, as indicated by increase in HOMA-R and decrease in PPARY levels in the DC group $(p<0.05)$. However, treatment with the $M$. oleifera extract reversed this trend via marked decrease in HOMA-R level and significant rise in PPARy level. In contrast, the extract had no effect on DPP-IV concentration in diabetic treated groups $(p<0.05)$.

Conclusion: These results indicate that $M$. oleifera leaf extract mitigates hyperglycemia in type 2 DM by modulating hyperinsulinemia, PPARY and inflammatory cytokines. Thus, the extract is a potential source of drug for the management of type 2 DM.
\end{abstract}

Keywords: Moringa oleifera, Diabetes mellitus, Streptozotocin, Peroxisome proliferator activated receptor-y, Dipeptidyl peptidase IV

This is an Open Access article that uses a fund-ing model which does not charge readers or their institutions for access and distributed under the terms of the Creative Commons Attribution License (http://creativecommons.org/licenses/by/4.0) and the Budapest Open Access Initiative (http://www.budapestopenaccessinitiative.org/read), which permit unrestricted use, distribution, and reproduction in any medium, provided the original work is properly credited.

Tropical Journal of Pharmaceutical Research is indexed by Science Citation Index (SciSearch), Scopus, International Pharmaceutical Abstract, Chemical Abstracts, Embase, Index Copernicus, EBSCO, African Index Medicus, JournalSeek, Journal Citation Reports/Science Edition, Directory of Open Access Journals (DOAJ), African Journal Online, Bioline International, Open-J-Gate and Pharmacy Abstracts

\section{INTRODUCTION}

Type 2 diabetes mellitus (DM) is believed to be the most prevailing chronic metabolic disorder with direct negative impact on the health of affected individuals. The $9^{\text {th }}$ edition of International Diabetes Federation of Middle East and North Africa (IDF MENA) region reported 
that in 2019, 426 million people were diagnosed with diabetes all over the world, out of which more than 55 million people are in the MENA region, and it has been projected that this number will increase to 108 million by 2045 [1]. It has been established that adipose tissue secretes biologically active mediators (adipocytokines or adipokines) which play an imperative role in the emergence of insulin resistance and type 2 DM [2].

PPARy belongs to nuclear receptor superfamily, and it regulates the expressions of adipokines. The activation of PPARy in visceral adipose tissue exerts inhibitory effect on inflammatory cytokine genes expression, thereby reducing the expressions of inflammatory cytokines such as IL-1 $\beta$, IL-6, and TNF $\alpha$. Previous studies reported that the activation of PPARy improves insulin sensitivity [3].

The management of diabetes with minimum adverse effect is a huge challenge to clinicians. Numerous attempts have been made to manage hyperglycemia in diabetes with synthetic drugs, but the drugs used in clinical practice are either too expensive or have undesirable side effects or contraindications [4]. Plant-derived medicines have received great attention due to their minimum side effects and relative affordability, when compared to synthetic drugs [5]. Thus, there is need to discover medicines from natural sources which can be used as alternatives to synthetic drugs for type 2 DM. Moringa oleifera (M. oleifera) commonly known as drumstick tree belongs to the family Moringaceae. It is a fastgrowing tree widely distributed in Red sea area (Jazan), Bangladesh, India, Pakistan, Afghanistan and parts of Africa where it is used in folk medicine [6]. The plant is cultivated on large scale for medicinal purposes in southern parts of Gizan. It is an edible plant with high nutritional and medicinal values, and it is used for the treatment of many diseases, hence the name "miracle tree" [7]. Phytochemical analyses of the leaves of $M$. oleifera have revealed that they are rich in minerals such as potassium, calcium, iron and phosphorous; vitamins A, C, D and E; amino acids and antioxidants such as flavonoids, $\beta$ carotene, and vitamin C [8]. Different parts of $M$. oleifera plant have been comprehensively studied in the treatment of various diseases such as typhoid fever, arthritis, malaria, swellings, skin diseases, parasitic diseases, hypertension, diabetes and liver disorder, and also for boosting the immune system in immuno-compromised patients, especially HIVIAIDS-related symptoms [9]. The traditional use of $M$. oleifera in diabetes is supported by previous published scientific studies on experimental animals [10]. Recently, it was reported that $M$. oleifera leaf extract demonstrated antidiabetic and antioxidant effects in experimental animal models of diabetes [11]. However, previous studies on the antidiabetic potential of $M$. oleifera were focused on assessment of its efficacy, while its possible underlying mechanisms in type $2 \mathrm{DM}$ are yet to be established. The traditional and medicinal values of $M$. oleifera which are supported by previous scientific findings formed the basis of the present research. Therefore, the current research was conducted to explore antidiabetic potential of the plant extract in a rat model of type $2 \mathrm{DM}$, and its underlying mechanisms.

\section{EXPERIMENTAL}

\section{Animals}

Male Wistar rats weighing 100 - $120 \mathrm{~g}$ were procured from the Medical Research Centre (MRC), a research unit of Jazan University. The rats were separated into six groups, having 6 rats in each. Standard laboratory temperature of 25 ${ }^{\circ} \mathrm{C}$ was maintained throughout the experimental period. This research was approved by the ethical approval committee of Jazan University (approval no. 0107/307/1439) and accomplished according to international guidelines [12].

\section{Collection of $M$. oleifera leaves}

Moringa oleifera plant is grown for commercial purposes in Jazan region of Saudi Arabia. A local farmer was contacted to provide the leaves of $M$. oleifera for research purpose. The $M$. oleifera plant was identified based on the literature, ethical knowledge and relevant resources, and the leaves were collected from the plant.

\section{Extraction of $M$. oleifera leaves}

The leaves were washed with water and kept under shed to dry. The dried leaves were crushed to powder with a commercial blender, and the powdered material $(1 \mathrm{~kg})$ was extracted by percolation using ethanol (95\%). The filtrate was filtered and left to dry at room temperature for 7 days. The extract was further subjected to freeze-drying to form a concentrate. The dried extract (concentrate) was kept in airtight container at $4{ }^{\circ} \mathrm{C}$. Prior to administration, the extract was suspended in $1 \% \mathrm{CMC}$ in distilled water.

\section{Chemicals and biochemicals (including kits)}

Streptozotocin was purchased from Sigma Aldrich Pvt Ltd. ELISA kits for insulin, PPARy, DDP-IV, IL-1 $1 \beta$, IL-6 and TNFa were purchased 
from MyBioSource, USA. All other chemicals and biochemicals from different manufacturers were purchased through authorized local suppliers in the Kingdom of Saudi Arabia.

\section{Preparation of high fat diet (HFD)}

HFD was prepared in the research laboratory using normal pellet diet (NPD), animal fat (lard), and a mixture of coconut oil and butter ghee. In this process, NPD (1000 g) was crushed into powder and blended with animal fat (20\%), coconut oil $(10 \%)$ and butter ghee $(10 \%)$. The mixture was then made into pellets and kept in a tray under shade to solidify. The dried pellet of HFD was stored in a refrigerator and given to groups II, III, IV and V rats in place of NPD for 4 weeks.

\section{Standardization of STZ dose for induction of type 2 DM}

Different doses of STZ were standardized to find a suitable dose for the induction of type $2 \mathrm{DM}$ in HFD-fed rats. Streptozotocin (STZ) was dissolved in $0.1 \mathrm{M}$ citrate buffer, $\mathrm{pH}$ 4.5. For this purpose, a pilot study was performed using 3 different doses of STZ (35, 40 and $45 \mathrm{mg} / \mathrm{kg}$ ). The STZ was intraperitoneally (i.p) injected into 3 different groups of rats, and their fasting glucose levels were checked after $72 \mathrm{~h}$. At a dose of 40 $\mathrm{mg} / \mathrm{kg}$, STZ increased blood glucose level above $200 \mathrm{mg} / \mathrm{dL}$ in all rats, clearly indicating development of type 2 DM. Therefore, $40 \mathrm{mg} / \mathrm{kg}$ was selected as the dose of STZ for induction of type 2 DM in HFD-fed rats.

\section{Experimental model of type 2 DM}

Streptozotocin (STZ) at a dose of $40 \mathrm{mg} / \mathrm{kg}$ was administered to groups II, III, IV and V rats to induce type 2 DM [13]. Fasting blood glucose level was determined after $72 \mathrm{~h}$ of STZ injection to confirm induction of type 2 DM. Rats with fasting glucose level $\geq 200 \mathrm{mg} / \mathrm{dL}$ were assumed to be diabetic.

\section{Treatment of groups}

Wistar rats $(n=36)$ were divided into six different groups. Group I (normal control, NC) was administered normal saline $(1 \mathrm{ml} / \mathrm{kg}, \mathrm{p} . \mathrm{o})$ for 21 days. Group II (diabetic control, DC) received STZ injection (40 mg/kg, i.p) after 4 weeks of HFD. Group III (diabetic treated) was given $M$. oleifera extract (100 mg/kg, orally) for 21 days. Group IV (diabetic treated) received M. oleifera (200 mg/kg, orally) for 21 days. Group V (diabetic treated) received $M$. oleifera (400 $\mathrm{mg} / \mathrm{kg}$, orally) for 21 days. Group VI (M. oleifera treated only) was given only $M$. oleifera (400 mg/kg, orally) for 21 days.

\section{Blood collection and serum preparation}

Blood was taken from the retro-orbital plexus of each rat after $72 \mathrm{~h}$ (to check induction of type 2 DM) and at the end of the study (after 21 days of $M$. oleifera dosing). The blood samples were collected in serum separation tubes and serum samples recovered after centrifugation were used for assay of biochemical parameters.

\section{Biochemical assays}

\section{Glucose}

Glucose level was estimated using assay kit which is based on the principle of glucose oxidase peroxidase [14].

\section{Oral glucose tolerance test (OGTT)}

The area under curve (AUC) of glucose was estimated using trapezoidal method [15]. The AUC was used for estimation of OGTT. Glucose solution $(2 \mathrm{~g} / \mathrm{kg}$ ) was given to $8 \mathrm{~h}$-fasted rats, and blood was withdrawn at the start (zero time) and subsequently at time intervals 30,60 and 120 min. Glucose levels were determined in each blood sample. The AUC of glucose was calculated as shown in Eq 1.

AUC $=$ [(fasting value + value at $30 \mathrm{~min}) \times 0.25]$ $+[($ value at $30 \mathrm{~min}+$ value at $60 \mathrm{~min}) \times 0.25]+$ [(value at $60 \mathrm{~min}+$ value at $120 \mathrm{~min}) \times 0.5$ ] (1)

\section{Insulin assay}

Insulin levels were assayed with ELISA kit which works on simple sandwich ELISA principle. In this technique, standards and test samples (serum) were added to a 96-well pre-coated with mouse specific anti-insulin antibody. Then, monoclonal antibody labelled with horseradish peroxidase (HRP) was added to the micro-plate well and subjected to incubation, after which the micro-plate was washed to remove free insulin. The TMB substrate reagent was added, and the absorbance of the yellow colour formed was measured at $450 \mathrm{~nm}$ in an ELISA reader. The concentrations of insulin in test samples were estimated by extrapolating the OD values of the samples from a standard calibration curve.

\section{Calculation of HOMA-R}

Insulin resistance was calculated based on HOMA-R as shown in Eq 2 [16]. 
HOMA-R $=\{(\mathrm{Fi} \times \mathrm{Fg}) / 22.5\} \ldots \ldots(2)$

where $\mathrm{Fi}$ and $\mathrm{Fg}$ are fasting insulin $(\mu \mathrm{U} / \mathrm{ml})$ and fasting glucose $(\mathrm{mmol} / \mathrm{l})$, respectively. The value of glucose in $\mathrm{mg} / \mathrm{dL}$ was converted to $\mathrm{mmol}$ (18 $\mathrm{mg} / \mathrm{dL}=1 \mathrm{mmol}$ ).

\section{Peroxisome proliferator activated receptor gamma (PPARY) assay}

ELISA kit was used to measure PPARy in an assay based on simple sandwich ELISA principle. In this technique, standards and test samples (supernatants of abdominal adipose tissue homogenates) were added to a 96-well micro-plate pre-coated with mouse-specific PPARy antibody. Then, biotinylated detection antibody and horseradish peroxidase (HRP) conjugates were added to each well of microplate and left to incubate, after which the microplate was washed to remove unbound components. Then, the TMB substrate reagent was added, and the absorbance of the yellow colour formed was measured at $450 \mathrm{~nm}$ in an ELISA reader. The concentrations of PPARy in test samples were determined by extrapolating the OD values of the samples from a standard curve.

\section{Dipeptidyl peptidase IV (DPP-IV) assay}

The concentration of DPP-IV was estimated in serum using sandwich ELISA principle. In this technique, standards or samples were added to a micro-plate pre-coated with anti-DPPIV antibody. Then, biotin-conjugated detection antibody and horseradish peroxidase (HRP) were added to micro-plate and washed with wash buffer. Thereafter, TMB substrate was added, and the absorbance of yellow colour formed was measured at $450 \mathrm{~nm}$ in an ELISA reader. The concentrations of DPPIV in test samples were determined by extrapolating the OD values of the samples from a standard curve.

Assay of inflammatory cytokines (II-1 $\beta$, IL-6 and TNFa)

ELISA kits were used to measure levels of IL-6, $\mathrm{IL}-1 \beta$ and TNF $\alpha$. The assay is based on simple sandwich ELISA principle. In this technique, standards and test samples (serum) were added to a 96-well micro-plate pre-coated with antibodies for IL-6, IL-1 $\beta$ and TNFa. Then, biotinylated detection antibody and horseradish peroxidase (HRP) conjugates were added to each well of micro-plate and subjected to incubation. After the incubation period, the microplate was washed to remove free/unbound components. Then, TMB substrate reagent was added, and the absorbance of the yellow colour formed was measured at $450 \mathrm{~nm}$ using ELISA reader. IL-6, IL-1 $\beta$ and TNF $\alpha$ concentrations in test samples were calculated by extrapolating the OD values of the samples from a standard curve.

\section{Statistical analysis}

The results were analyzed by one-way ANOVA using GraphPad Prism 8.3. Groups were compared with each other and differences observed were deemed to be statistically significant at $p<0.05$.

\section{RESULTS}

\section{Blood glucose level}

Diabetic control (DC) group had significantly increased glucose level than that of NC group $(p<0.001)$, which is depicted in Table 1. However, treatment with extract of $M$. oleifera $(100,200$ and $400 \mathrm{mg} / \mathrm{kg}$ ) led to significant decreases in blood glucose levels in comparison to DC group $(p<0.001)$. However, no significant difference in blood glucose level between $M$ oleifera per se group and NC group was documented $(p>0.05)$.

\section{Oral glucose tolerance test}

A significant upsurge in AUC of glucose was observed in DC group, relative to NC group ( $p<$ 0.001 ) which is illustrated in Table 1 . In contrast, there were significant decreases in glucose AUC in groups treated with $M$. oleifera extract at doses 100,200 and $400 \mathrm{mg} / \mathrm{kg}(p<0.001)$, relative to DC group. However, no significant variation in AUC of glucose was documented between $M$. oleifera alone and NC group ( $p>0.05)$.

Table 1: Effect of $M$. oleifera leaf extract on fasting glucose and AUC of glucose in type 2 diabetic rats

\begin{tabular}{llcc}
\hline Group & Treatment & $\begin{array}{c}\text { Glucose level } \\
(\mathbf{m g} / \mathbf{d L})\end{array}$ & $\begin{array}{c}\text { AUC of } \\
\text { glucose }\end{array}$ \\
\hline I & $\begin{array}{l}\text { Normal control } \\
\text { group }\end{array}$ & $92.83 \pm 5.94$ & $12.92 \pm 0.51$ \\
II & $\begin{array}{l}\text { Type 2 diabetic } \\
\text { control group }\end{array}$ & $292.00 \pm 11.82^{\mathrm{a}}$ & $37.80 \pm 0.74^{\mathrm{a}}$ \\
III & $\begin{array}{l}\text { Type 2 diabetic } \\
\text { treated group }\end{array}$ & $231.67 \pm 9.34^{\mathrm{y}}$ & $28.10 \pm 0.82^{\mathrm{y}}$ \\
IV & $\begin{array}{l}\text { Type 2 diabetic } \\
\text { treated group }\end{array}$ & $194.00 \pm 5.44^{\mathrm{y}}$ & $23.25 \pm 0.65^{\mathrm{y}}$ \\
V & $\begin{array}{l}\text { Type 2 diabetic } \\
\text { treated group }\end{array}$ & $153.67 \pm 7.26^{\mathrm{y}}$ & $19.32 \pm 0.73^{\mathrm{y}}$ \\
VI & $\begin{array}{l}\text { M. oleifera per } \\
\text { se group }\end{array}$ & $87.83 \pm 4.06^{\mathrm{ns}}$ & $11.85 \pm 0.48^{\mathrm{ns}}$ \\
\hline${ }^{\mathrm{a}} P<0.001$ compared to NC; ${ }^{\mathrm{y}} p<0.001$ & compared to \\
DC; ${ }^{\mathrm{ns}} p>0.05$ compared to NC
\end{tabular}

Trop J Pharm Res, January 2021; 20(1): 98 


\section{Insulin levels}

A significant increase in insulin level was observed in DC group, relative to NC group (Table 2). However, daily dosing with extract of M. oleifera $(100,200$ and $400 \mathrm{mg} / \mathrm{kg}$ ) reduced insulin levels significantly $(p<0.01, p<0.001)$, in comparison to DC group. Insulin levels in the group given $M$. oleifera only and NC group were comparable $(p>0.05)$.

\section{HOMA-R level}

Table 2, HOMA-R level was markedly increased in DC group, relative to NC group as shown in Table 2. $(p<0.001)$. However, the elevated level of HOMA-R was reduced significantly $(p<0.001)$ after administration of extract ( $M$. oleifera) at doses 100,200 and $400 \mathrm{mg} / \mathrm{kg}$, relative to the DC group. There was no significant variation in HOMA-R level between only $M$. oleifera per se group and the NC group $(p>0.05)$.

Table 2: Effect of $M$. oleifera leaf extract on insulin and HOMA-R levels in type 2 diabetic rats

\begin{tabular}{llcl}
\hline Group & Treatment & $\begin{array}{c}\text { Insulin } \\
\text { level } \\
(\mu \mathrm{U} / \mathrm{mL})\end{array}$ & HOMA-R \\
\hline I & $\begin{array}{l}\text { Normal control } \\
\text { group }\end{array}$ & $5.44 \pm 0.32$ & $1.25 \pm 0.10$ \\
II & $\begin{array}{l}\text { Type 2 diabetic } \\
\text { control group }\end{array}$ & $10.03 \pm 0.27^{\mathrm{a}}$ & $6.71 \pm 0.41^{\mathrm{a}}$ \\
$\mathrm{III}$ & $\begin{array}{l}\text { Type 2 diabetic } \\
\text { treated group }\end{array}$ & $8.68 \pm 0.19^{\mathrm{x}}$ & $4.97 \pm 0.28^{\mathrm{x}}$ \\
IV & $\begin{array}{l}\text { Type 2 diabetic } \\
\text { treated group }\end{array}$ & $7.97 \pm 0.25^{\mathrm{y}}$ & $2.83 \pm 0.24^{\mathrm{y}}$ \\
$\mathrm{V}$ & $\begin{array}{l}\text { Type 2 diabetic } \\
\text { treated group }\end{array}$ & $7.25 \pm 0.31^{\mathrm{y}}$ & $1.14 \pm 0.09^{\mathrm{y}}$ \\
$\mathrm{VI}$ & $\begin{array}{l}\text { M. oleifera per se } \\
\text { group }\end{array}$ & $5.25 \pm 0.27^{\mathrm{ns}} 54.66 \pm 1.56^{\mathrm{ns}}$ \\
\hline $\begin{array}{l}{ }^{\mathrm{a}} P<0.001 \text { compared to } \mathrm{NC} ;{ }^{\mathrm{x}} p<0.01,{ }^{\mathrm{y}} p<0.001 \\
\text { compared to DC; }{ }^{\text {ns }} p>0.05 \text { compared to NC }\end{array}$
\end{tabular}

\section{PPARy levels}

PPARy level in adipose tissue was significantly reduced in DC group, in comparison to NC group $(p<0.001$; Figure 1). However, daily administration of extract of $M$. oleifera led to significant increase in PPARy levels, in comparison to DC group $(p<0.001)$. In contrast, no significant variation in PPARy level was documented between $M$. oleifera alone and NC group $(p>0.05)$.

\section{DPP-IV concentration}

There was markedly higher concentration of DPP-IV in the DC group in comparison to NC group ( $p<0.01$; Figure 2$)$. Daily administration of
M. oleifera leaf extract demonstrated no significant decrease in DPP-IV concentration at doses 100,200 and $400 \mathrm{mg} / \mathrm{kg}$, when compared to DC group ( $p>0.05)$. In contrast, no significant variation in DPP-IV level was documented between $M$. oleifera alone and NC group ( $p>$ 0.05).

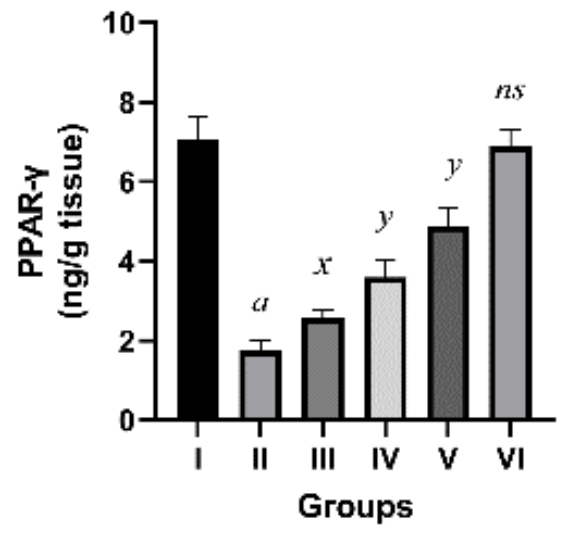

Figure 1: PPARy levels in the supernatant of adipose tissue homogenate in NC, DC and $M$. oleifera treated groups. ${ }^{a} p<0.001$ versus NC; ${ }^{x} p<0.01,{ }^{y} p<0.001$ versus $\mathrm{DC} ;{ }^{\mathrm{ns}} p>0.05$ versus NC

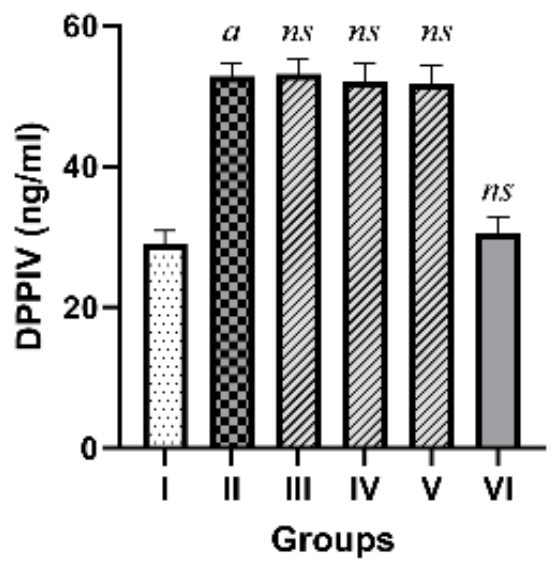

Figure 2: DPP-IV concentration in serum of NC, DC and $M$. oleifera treated groups. ${ }^{a} P<0.001$ versus NC; ${ }^{\mathrm{ns}} p>0.05$ versus DC and NC

\section{Cytokines (IL-6, IL-1 $\beta$ and TNF $\alpha$ ) levels}

The levels of IL-6, IL-1 $\beta$ and TNFa were augmented significantly in DC group, when compared to NC group (Figure 3, Figure 4 and Figure 5). However, following daily administration of M. oleifera extract $(100,200$ and $400 \mathrm{mg} / \mathrm{kg})$, there were marked decrease in the levels of these cytokines (IL-6, IL-1 $\beta$ and TNF $\alpha$ ), relative to the DC group $(p<0.001)$. However, no significant variation in levels of IL-6, IL-1 $\beta$ and 
TNFa were documented between $M$. oleifera alone and the NC group $(p>0.05)$.

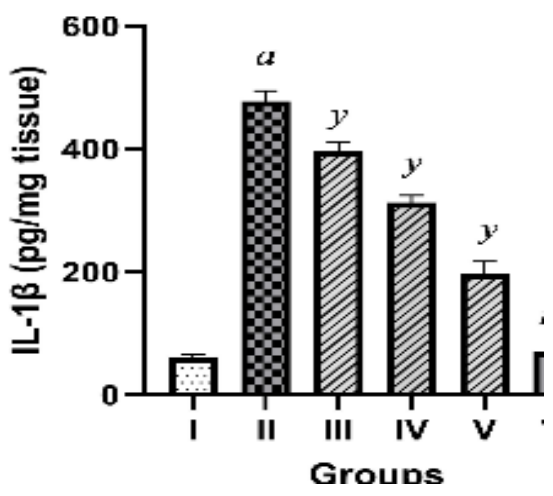

Figure 3: Levels of IL-1 $\beta$ in NC, DC and $M$. oleifera treated groups. ${ }^{\mathrm{a}} P<0.001$ versus $\mathrm{NC} ;{ }^{\mathrm{y}} p<0.001$ versus $\mathrm{DC} ;{ }^{\mathrm{ns}} p>0.05$ versus NC

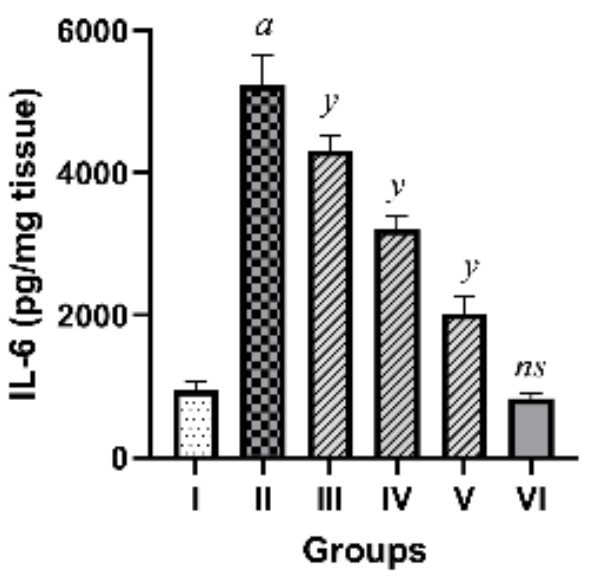

Figure 4: Levels of IL-6 in NC, DC and $M$. oleifera treated groups. ${ }^{a} P<0.001$ versus $\mathrm{NC} ;{ }^{\mathrm{y}} p<0.001$ versus $D C ;{ }^{n s} p>0.05$ versus NC

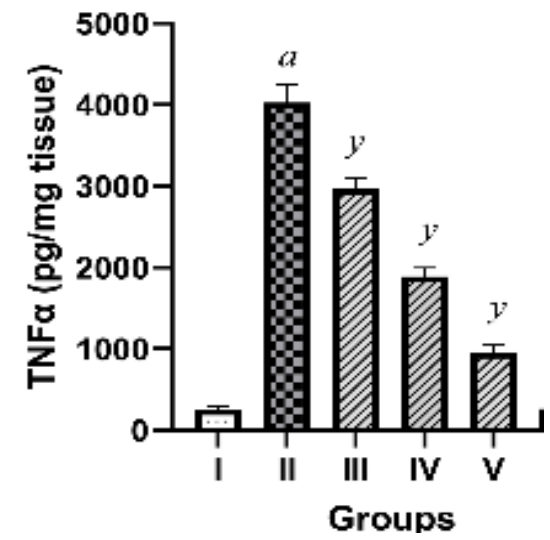

Figure 5: Levels of TNFa in NC, DC and M. oleifera treated groups. ${ }^{a} P<0.001$ versus $\mathrm{NC} ;{ }^{y} p<0.001$ versus DC; ${ }^{\mathrm{ns}} p>0.05$ versus NC

\section{DISCUSSION}

Type 2 DM is the most prevalent form of diabetes: it accounts for more than $90 \%$ of all diabetes cases throughout the world. It is characterized by persistent hyperglycemia, which is associated with reduced secretion of insulin and/or decreased insulin sensitivity in target tissues that leads to development of insulin resistance. Continuous and prolonged hyperglycemia in diabetes is generally associated with microvascular and macrovascular complications [17]. Previous research findings have indicated that low-dose STZ injection to high fat diet-fed animals produced marked hyperglycemia and poor glycemic control, as evidenced in increased levels of $\mathrm{HbA} 1 \mathrm{c}$ and impairment of glucose tolerance [13].

The present study has demonstrated that lowdose STZ administration produced sustained hyperglycemia in HFD-fed Wistar rats. However, administration of $M$. oleifera extract for 21 days significantly reduced glucose level, which clearly indicates antihyperglycemic effect. These findings are supported by previous published research asserting that $M$. oleifera leaf extract significantly reduced glucose levels in type 2 DM [18]. However, the study did not establish the mechanism underlying antihyperglycemic effect of the extract. Hence, the present study was performed to investigate and establish the potential mechanism underlying antihyperglycemic effect of $M$. oleifera in a rat model of type 2 DM.

If left untreated, sustained hyperglycemia may lead to impairment of glucose tolerance (IGT) which eventually results in type $2 \mathrm{DM}$. It has been suggested that impairment of glucose tolerance is due to decreased utilisation of glucose by peripheral tissues [19]. An investigation of OGTT is usually carried out to determine whether the patient has IGT, especially when the fasting blood glucose level is within the normal range. The present study revealed that AUC of glucose was significantly higher in type 2 DC group subjected to OGTT by administration of glucose solution (2 $\mathrm{g} / \mathrm{kg})$. However, administration of $M$. oleifera leaf extract led to significant reduction in AUC of glucose after an OGTT.

Previous research studies have demonstrated that obesity is correlated with insulin resistance $(\mathrm{IR})$ in diabetic patients [20]. Insulin resistance is a condition in which normal concentration of insulin is unable to bind to insulin receptors in liver, muscle and fat cells, leading to inability to 
accomplish adequate biological response in diabetic patients. When insulin resistance-like situation arises, the pancreatic $\beta$-cells compensate by secreting high levels of insulin to control hyperglycemia, resulting in hyperinsulinemia 21]. The results of this study clearly established significant hyperinsulinemia in type 2 DC group. However, daily administration of $M$. oleifera extract for 21 days significantly prevented hyperinsulinemia by reducing insulin levels. In the present study, it was assumed that the extract may ameliorate insulin resistance. Therefore, HOMA-R, an index for IR was calculated. The results indicated significant augmentation in HOMA-R level in type 2 DC group. However, M. oleifera leaf extract markedly reduced the level of HOMA-R.

In addition to IGT, there is an association between hyperinsulinemia and IR in type $2 \mathrm{DM}$. This is likely due to excessive secretion of insulin from pancreatic $\beta$-cells and downregulation of insulin receptor or dysfunction in post-receptor signalling. Previous research findings indicate that nuclear PPAR-y modulation demonstrates a significant role in controlling hyperglycemia in type 2 DM [22]. Clinicians usually prescribe PPAR-y agonists which act by improving the sensitivity of insulin towards its receptor and also by enhancing the recruitment of glucose transporters. In the present study, it was observed that PPAR-y level was significantly reduced in type 2 DC group. However, $M$. oleifera leaf extract administration for 21 days significantly increased PPAR-y levels in abdominal adipose tissue.

Dipeptidyl peptidase IV is a transmembrane glycoprotein which inactivates incretin hormones such as GLP-1 and GIP. These hormones maintain glucose homeostasis by stimulating insulin secretion and inhibiting glucagon secretion. Numerous inhibitors of DPP-IV are commercially available for treating type $2 \mathrm{DM}$ [23]. In recent years, researchers have made efforts to identify new and effective anti-DPP-IV drugs from natural sources [24]. Therefore, the inhibitory potential of $M$. oleifera leaf extract on DPP-IV was investigated. The results revealed that the concentration of DPP-IV was significantly increased in type 2 DC group. However, $M$. oleifera leaf extract administration for 21 days did not produce any significant decrease in the concentration of DPP-IV. Thus, M. oleifera leaf extract had no inhibitory effect on DPP-IV.

It has been reported that inflammatory cytokines demonstrate significant role in IR pathogenesis via impairment in insulin receptor substrate (IRS) phosphorylation [25].
It has also been established by previous researchers that inflammatory cytokines stimulate I-kappa-beta kinase- $\beta$ and I-kappa- $\alpha$, thus facilitating insulin resistance by activating nuclear factor kappa- $\beta$ (NFk $\beta$ ) [26]. In a previous work, it was reported that activation of inflammatory pathway increased the expressions of IL-6, IL-1 $\beta$ and TNF- $\alpha$ and established an IRlike situation [20]. The present study revealed significant rise in levels of IL-6, IL- $1 \beta$ and TNF- $\alpha$ in type 2 DC group. However, daily administration of $M$. oleifera extract significantly reduced elevated levels of these cytokines, thereby exerting anti-inflammatory properties.

\section{CONCLUSION}

This study has demonstrated that $M$. oleifera leaf extract reduces the levels of blood glucose, AUC of glucose, insulin and inflammatory cytokines (IL6, IL-1 \& TNF $\alpha$ ) in type 2 diabetic rats. Moreover, the extract reduces HOMA-R values and improves PPARy levels, but has no significant inhibitory effect on DPP-IV. These findings suggest that $M$. oleifera leaf extract exerts antihyperglycemic effect through a mechanism involving modulation of hyperinsulinemia, PPARy and inflammatory cytokines, and could therefore be developed for the management of diabetes mellitus.

\section{DECLARATIONS}

\section{Acknowledgement}

This research project was financially supported by Scientific Research Deanship, Jazan University under research grant 8 (Research proposal no. JUP8/378). The authors highly appreciate the financial assistance rendered by Scientific Research Deanship, Jazan University, Gizan, Saudi Arabia.

\section{Disclosure statement}

No conflict of interest is associated with this research.

\section{Author's contribution}

We declare that this work was carried out by Tarique Anwer, Mohammed M Safhi, Hafiz A Makeen, Saeed Alshahrani, Rahimullah Siddiqui, SM Sivakumar, Emad S Shaheen, and Mohammad Firoz Alam, and all responsibilities pertaining to claims relating to the content of this article will be borne by the authors. 


\section{Open Access}

This is an Open Access article that uses a funding model which does not charge readers or their institutions for access and distributed under the terms of the Creative Commons Attribution License (http://creativecommons.org/licenses/by/ 4.0) and the Budapest Open Access Initiative (http://www.budapestopenaccessinitiative.org/rea d), which permit unrestricted use, distribution, and reproduction in any medium, provided the original work is properly credited.

\section{REFERENCES}

1. IDF Diabetes Atlas 9th edition. International Diabetes Federation 2019 https://www.diabetesatlas.org/en/resources/

2. Fuentes E, Guzman-Jofre L, Moore-Carrasco R, Palomo I. Role of PPARs in inflammatory processes associated with metabolic syndrome (Review). Mol Med Rep 2013; 8(6): 1611-1616.

3. Hosni AA, Abdel-Moneim AA, Abdel-Reheim ES, Mohamed SM, Helmy H. Cinnamaldehyde potentially attenuates gestational hyperglycemia in rats through modulation of PPAR, pro-inflammatory cytokines and oxidative stress. Biomed Pharmacother 2017; 88: 52-60.

4. Chukwuma $\mathrm{Cl}$, Matsabisa MG, Ibrahim MA, Erukainure OL, Chabalala MH, Islam MS. Medicinal plants with concomitant anti-diabetic and anti-hypertensive effects as potential sources of dual acting therapies against diabetes and hypertension: A review. J Ethnopharmacol 2019; 235: 329-360.

5. Anwer T, Sharma M, Khan G, lqbal M, Ali MS, Alam MS, Safhi MM, Gupta N. Rhus coriaria ameliorates insulin resistance in non-insulin-dependent diabetes mellitus (NIDDM) rats. Acta Pol Pharm 2013; 70(5): 861-867.

6. Leone A, Spada A, Battezzati A, Schiraldi A, Aristil J, Bertoli S. Cultivation, genetic, ethnopharmacology, phytochemistry and pharmacology of Moringa oleifera leaves: An overview. Int J Mol Sci 2015; 16(6): 1279112835.

7. Gopalakrishnan L, Doriya K, Kumar DS. Moringa oleifera: $A$ review on nutritive importance and its medicinal application. Food Sci Hum Wellness 2016; 5: 49-56.

8. Adepoju-Bello AA, Jolayemi OM, Ehianet TS, Ayoola GA. Preliminary phytochemical screening, antioxidant and antihyperglycaemic activity of Moringa oleifera leaf extracts. Pak J Pharm Sci 2017; 30(6): 2217-2222.

9. Kou $X$, Li B, Olayanju JB, Drake JM, Chen $N$. Nutraceutical or pharmacological potential of Moringa oleifera Lam. Nutrients 2018; 10(3): 343.

10. Yassa HD, Tohamy AF. Extract of Moringa oleifera leaves ameliorates streptozotocin-induced diabetes mellitus in adult rats. Acta Histochem 2014; 116(5): 844854.

11. Bamagous GA, Al Ghamdi SS, Aziz Ibrahim IA, Mahfoz AM, Afify MA, Alsugoor MHM, Shammah AA, Arulselvan
$P$, Rengarajan T. Antidiabetic and antioxidant activity of ethyl acetate extract fraction of Moringa oleifera leaves in STZ-induced diabetes rats via inhibition of inflammatory mediators. Asian Pac J Trop Biomed 2018; 8(6): 320-327.

12. Clark JD, Gebhart GF, Gonder JC, Keeling ME, Kohn DF. The 1996 guide for the care and use of laboratory animals. Ilar Journal 1997; 38(1): 41-48.

13. Suman RK, Mohanty IR, Borde MK, Maheshwari $U$, Deshmukh YA. Development of an experimental model of diabetes co-existing with metabolic syndrome in rats. Adv Pharmacol Sci 2016; 2016: 9463476.

14. Braham D, Trinder $P$. An improved colour reaction for the determination of blood glucose by oxidase system. Analyst 1972; 97(151): 142-145.

15. Sakaguchi K, Takeda M, Maeda M, Ogawa W, Sato T, Okada S, Ohnishi Y, Nakajima H, Kashiwagi A. Glucose area under the curve during oral glucose tolerance test as an index of glucose intolerance. Diabetol Inter 2015; 7(1): 53-58

16. Matthews DR, Hosker JP, Rudenski AS, Naylor BA, Treacher DF, Turner RC. Homeostasis model assessment: insulin resistance and beta-cell function from fasting plasma glucose and insulin concentrations in man. Diabetologia 1985; 28: 412-419.

17. Anwer T, Sharma M, Khan G, Alam MF, Alam MS, Ali MS. Preventive role of Withania somnifera on hyperlipidemia and cardiac oxidative stress in streptozotocin induced type 2 diabetic rats. Trop $J$ Pharm Res 2017; 16 (1): 119-125.

18. Jaiswal D, Rai PK, Mehta S, Chatterji S, Shukla S, Rai DK, Sharma G, Sharma B, Khair S, Watal G. Role of Moringa oleifera in regulation of diabetes induced oxidative stress. Asian Pac J Trop Med 2013; 426-432.

19. Anwer T, Sharma M, Pillai KK, Iqbal M. Effect of Withania somnifera on insulin sensitivity in non-insulin dependent diabetes mellitus (NIDDM) rat. Basic Clin Pharmacol Toxicol 2008; 102: 498-503.

20. Safhi MM, Anwer T, Khan G, Siddiqui R, Sivakumar SM, Alam MF. The combination of canagliflozin and omega-3 fatty acid ameliorates insulin resistance and cardiac biomarkers via modulation of inflammatory cytokines in type 2 diabetic rats. Korean J Physiol Pharmacol 2018; 22(5): 493-501.

21. Anwer T. Melatonin ameliorates hyperinsulinemia, glucose intolerance and insulin resistance in STZnicotinamide induced type2 diabetic rats. Intern J Pharm Pharmaceut Sci 2014; 6(2): 133-136.

22. Huang TH, Peng G, Kota BP, Li GQ, Yamahara J, Roufogalis BD, Li Y. Anti-diabetic action of Punica granatum flower extract: activation of PPAR-gamma and identification of an active component. Toxicol Appl Pharmacol 2005; 207(2):160-169.

23. Suman RK, Mohanty IR, Maheshwar U, Borde MK, Deshmuskh YA. Natural dipeptidyl peptidase-IV inhibitor mangiferin mitigates diabetes and metabolic syndromeinduced changes in experimental rats. Diabetes Metab Syndr Obes 2016; 9: 261-272.

Trop J Pharm Res, January 2021; 20(1): 102 
24. Lu Y, Lu P, Wang Y, Fang $X$, Wu J, Wang $X$. A Novel dipeptidyl peptidase-IV inhibitory tea peptide improves pancreatic $\beta$-cell function and reduces $\alpha$-cell proliferation in streptozotocin-induced diabetic mice. Int $\mathrm{J} \mathrm{Mol} \mathrm{Sci}$ 2019; 20: 322.

25. Sosale B, Chandrashekar, S, Aravinda SR, Renuka $P$, Anupama KR. Influence of cytokine status on insulin resistance and circulating endothelial progenitor cells in type 2 diabetes mellitus. Cytokine 2017; 99: 179-185.

26. Mahmoud F, Al-Ozairi E, Haines D, Novotny L, Dashti A, Ibrahim B, Abdel-Hamid M. Effect of Diabetea teaTM consumption on inflammatory cytokines and metabolic biomarkers in type 2 diabetes patients. J Ethnopharmacol 2016; 194: 1069-1077. 